\title{
Implementasi Sistem Informasi Pembayaran SPP Berbasis Web (Studi Kasus : SMK Arrahman Tangerang)
}

\author{
Nur Azizah ${ }^{1}$, Mohamad Warid ${ }^{* 2}$, Arif Hidayatulloh ${ }^{3}$ \\ ${ }^{1,3}$ Program Studi Sistem Informasi Fakultas Sains dan Teknologi Universitas Raharja, ${ }^{2}$ Program \\ Studi Sistem Komputer Fakultas Sains dan Teknologi Universitas Raharja \\ E-mail: ${ }^{1}$ nur.azizah@ @ raharja.info, ${ }^{* 2}$ warid@ raharja.info, ${ }^{3}$ arifhidayat@ raharja.info
}

\begin{abstract}
Abstrak
Pembayaran SPP masih sering mengalami kendala seperti pendataan serta proses informasi pembayaran yang dilakukan selama ini digunakan masih sederhana (semikomputerisasi) hanya menggunakan microsoft excel dalam penginputan laporannya, oleh karena itu sering terjadi masalah dalam pembuatan laporan untuk siswa/i dalam melakukan pembayaran spp tersebut dibutuhkan secara tepat dan akurat sehingga belum mampu menghasilkan suatu sistem informasi pembayaran spp berbasis web yang dibutuhkan. Pada era teknologi saat ini perlu adanya inovasi penggunaan teknologi dalam dunia pendidikan untuk membantu administrasi keuangan sekolah agar pendataan serta proses informasi Pembayaran berjalan dengan efektif dan efesien. Dalam jurnal ini akan membahas tentang perancangan sistem informasi pembayaran SPP berbasis web. Perancangan ini bertujuan untuk membantu bagian keuangan dalam mendata pembayaran SPP. Metode penelitian yang digunakan adalah metode SDLC jenis Waterfall. aplikasi ini membantu bagian keuangan dalam mendata pembayaran SPP.
\end{abstract}

Kata Kunci-Pembayaran SPP, Sistem, Informasi

\begin{abstract}
SPP payments still often experience problems such as data collection and the payment information process that has been used so far is still simple (semicomputerization) using only Microsoft Excel in inputting reports, therefore there are often problems in making reports for students in making spp payments required. precise and accurate so that it has not been able to produce a web-based SPP payment information system needed. In the current technological era, it is necessary to innovate the use of technology in the world of education to assist the administration of school finances so that the data collection and information process of Payments run effectively and efficiently. In this journal, we will discuss about designing a webbased SPP payment information system. This design aims to assist the finance department in recording SPP payments. The research method used is the SDLC type Waterfall method. This application helps the finance department in recording SPP payments.
\end{abstract}

Keywords-SPP Payment, System, Information 


\section{PENDAHULUAN}

Perkembangan ilmu pengetahuan dan teknologi saat ini khususnya dalam bidang komputerisasi sudah berkembang pesat, sehingga peranan komputer sangat membantu untuk menyelesaikan pekerjaan dalam berbagai bidang pekerjaan dan pendidikan karena dengan penggunaan komputer dapat menghemat waktu, biaya sehingga bisa memberikan hasil yang memuaskan.

Dalam kegiatan transaksi Pembayaran SPP, tentu adanya sebuah sistem yang diberlakukan demi kelancaran transaksi tersebut. Sistem tersebut mencakup prosedur yang digunakan dalam Pembayaran SPP, bagaimana dalam hal pencatatan transaksi yang terjadi. Untuk memudahkan proses pengolahan data transaksi yang terjadi sampai kepada pembuatan laporan, sangat dibutuhkan sebuah sistem informasi Pembayaran SPP. Karena sistem informasi administrasi merupakan langkah awal untuk dapat terlaksananya suatu kegiatan. Sistem pembayaran SPP pada SMK Arrahman Tangerang yang berjalan saat ini masih semikomputerisasi sehingga memperlambat kinerja dari bagian Tata Usaha.

Berdasarkan pada persoalan yang dihadapi oleh SMK Arrahman Tangerang, perlu dibuat sistem informasi yang dapat mengatasi persoalan tersebut dengan memanfaatkan teknologi informasi terbaru yang sudah ada untuk mengatasi permasalahan yang dialami serta dapat berkontribusi bagi peningkatan kinerja dari bagian TU. Perancangan dan implementasi perangkat lunak dalam komputer perlu dilakukan dan akan memiliki dampak positif jika memiliki perangkat lunak yang dapat digunakan untuk mengatasi permasalahan yang dialami serta dapat berkontribusi bagi peningkatan kinerja dari bagian pembayaran SPP. Sistem informasi pembayaran SPP berbasis Web diharapkan dapat membantu bagian administrasi keuangan dalam mengelola pembayaran SPP.

\subsection{Tinjaun Pustaka}

\subsubsection{Pembayaran}

Menurut Evy (2019:54), Ada dua pengertian pembayaran yaitu pengertian secara sempit dan yuridis teknis. Pengertian pembayaran dalam arti sempit, adalah pelunasan utang oleh debitur kepada kreditur. Pembayaran seperti ini dilakukan dalam bentuk uang atau barang. Namun, pengertian pembayaran dalam arti yuridis tidak hanya dalam bentuk uang atau barang, tetapi juga dalam bentuk jasa, seperti jasa dokter dan lain-lain.

\subsection{2. $S P P$}

Menurut Ely (2014:80), SPP(Sumbangan Pembinaan Pendidikan) adalah biaya yang dibebankan kepada mahasiswa yang harus dibayar per semester selama menjadi mahasiswa. Besaran SPP juga beragam baik antara mahasiswa program diploma/sarjana dan program pascasarjana, maupun antara mahasiswa local dan mahasiswa asing.

\subsubsection{Web}

Menurut Beranda Agency dalam buku "Menggali Harta Karun Internet" (2010:10), menjelaskan bahwa World Wide Web (www) atau disebut dengan istilah web merupakan layanan yang sangat banyak digunakan dalam internet dimana terdiri atas kumpuan dokumen elektronik dari seluruh Negara. Setiap dokumen elektronik dalam web disebut sebagai halaman web (Web Page), yang dapat menyimpan teks, gambar, audio, dan video. Selain itu, halamanhalaman web biasanya tersambung ke dokumen-dokumen lainnya. 


\subsection{Literature Review}

Banyak penelitian yang sebelumnya dilakukan mengenai sistem pembayaran SPP dari penelitian lain yang berkaitan. Dalam upaya mengembangkan dan menyempurnakan sistem tersebut diperlukan studi pustaka (literature review) sebagai salah satu dari penerapan metode penelitian yang dilakukan diantaranya yaitu:

1. Penelitian yang dilakukan oleh Desi Purwanti (2011), yang berjudul "Perancangan Sistem Administrasi Pembayaran Sekolah Berbasis Web Pada SMA Negeri 6 Tangerang". Metode yang diusulkan pada penelitian ini pemograman dirancang dengan aplikasi Macromedia Dreamweaver, XAMPP dan database MySQL. Belum adanya peringatan terhadap sistem apabila orang yang ingin melakukan tindak kejahatan atau memanipulasi data. Penelitian akan dikembangkan lagi dengan sistem yang dapat menghasilkan output secara cepat berupa kwitansi sebagai pergantian tanda bukti kartu iuran, agar menghemat biaya yang dikeluarkan pihak sekolah untuk cetak.

2. Penelitian yang dilakukan oleh Moch. Mastur Bayhaqi (2011), yang berjudul "Perancangan Sistem Admiinistrasi Pembayaran Sekolah Pada SMK Global Tangerang Berbasis Web". Metode yang diusulkan pada penelitian ini menggunakan program Visual Paradigma for UML 6.4 untuk menggambarkan Use Case Diagram, Sequance Diagram, State Diagram, Activity Diagram,. Untuk membantu bagian keuangan dalam melakukan pekerjaan yang meliputi penginputan data siswa sampai dengan pembuatan laporan keuangan per periode. Dan system pengarsipan data yang lebih aman dan tidak tumpang tindih. Sistem ini diharapkan bias meningkatkan pelayananan dan kenyamanan terhadap para siswa SMK Global Tangerang yang melakukan transaksi pembayaran.

3. Penelitian yang dilakukan oleh Sanita (2010) yang berjudul "Perancangan Sistem Pembayaran SPP Sekolah Berbasis Web Pada SMP PGR1 396 Kelapa Dua". Metode yang diusulkan pada penelitian ini pemograman dirancang dengan aplikasi Macromedia Dreamweaver, XAMPP dan database MySQL. Untuk membantu divisi keuangan, sistem ini dirancang untuk dijadikan solusi awal dalam memecahkan masalah yang dihadapi oleh divisi keuangan. Namun belum adanya keluaran (output) berupa kwitansi sebagai tanda bukti pembayaran yang cepat dan efisien. Dan belum adanya peringatan terhadap sistem apabila orang yang ingin melakukan tindak kejahatan atau memanipulasi data. Penelitian akan dikembangkan lagi dengan sistem yang dapat menghasilkan output secara cepat berupa kwitansi sebagai pergantian tanda bukti kartu iuran, agar menghemat biaya yang dikeluarkan pihak sekolah untuk cetak.

\section{METODE PENELITIAN}

Metode penelitian merupakan suatu tata cara atau kegiatan pelaksanaan penelitian rangka untuk mengumpulkan informasi atau data serta melakukan investigasi terhadap data yang telah didapatkan tersebut. yang didasari oleh asumsi-asumsi dasar, pandangan-pandangan filosofis dan ideologis, pertanyaan dan isu-isu yang dihadapi. Suatu penelitian mempunyai rancangan penelitian tertentu. Rancangan ini menggambarkan prosedur atau langkah-langkah yang harus ditempuh, waktu penelitian, sumber data dan kondisi arti untuk apa data dikumpulkan dan dengan cara bagaimana data tersebut dihimpun dan diolah untuk dianalisa dalam pembuatan laporan.

\subsection{Metode Pengumpulan Data}

\subsubsection{Metode Observasi (Observasi Research)}


Melakukan analisa masalah yang ada dengan cara mengamati sumber dan pengolahan data serta mengumpulkan data dari bagian-bagian yang berhubungan dengan pembayaran SPP disekolah pada SMK Arrahman Tangerang, seperti bagian Tata Usaha.

\subsubsection{Metode Wawancara (Interview Research)}

Penulis melakukan wawancara dengan bagian terkait berupa tanya jawab langsung dengan pihak yang berkepentingan dan memahami hal yang ingin diteliti sesuai dengan tujuan penelitian.

\subsubsection{Metode Studi Pustaka (Studi Literature)}

Dengan metode ini penulis berusaha melengkapi data-data yang diperoleh dari bukubuku yang ada yaitu buku tentang Kurikulum tingkat satuan pendidikan SMK Arrahman Tangerang untuk membantu menulis dalam menyusun sebuah laporan.

\section{2. $\quad$ Metode Analisis Data}

Pada penelitian ini, metode analisa dilakukan dengan langkah-langkah melakukan pengamatan dan analisa terhadap sistem yang berjalan saat ini, serta menentukan UML (Unified Modeling Language) yang meliputi use case diagram, activity diagram, sequence diagram.

\subsection{Metode Pengembangan Sistem}

Metode yang digunakan pada pengembangan perangkat lunak ini menggunakan waterfall. Menurut Yurindra (2017:41). Waterfall merupakan model yang membangun perangkat lunak berdasarkan Daur Hidup Perangkat Lunak (SDLC), yaitu model yang mempunyai struktur yang dimulai dari Perencanaan, Analisis, Design dan Implementasi. Seperti yang disajikan pada gambar 1.

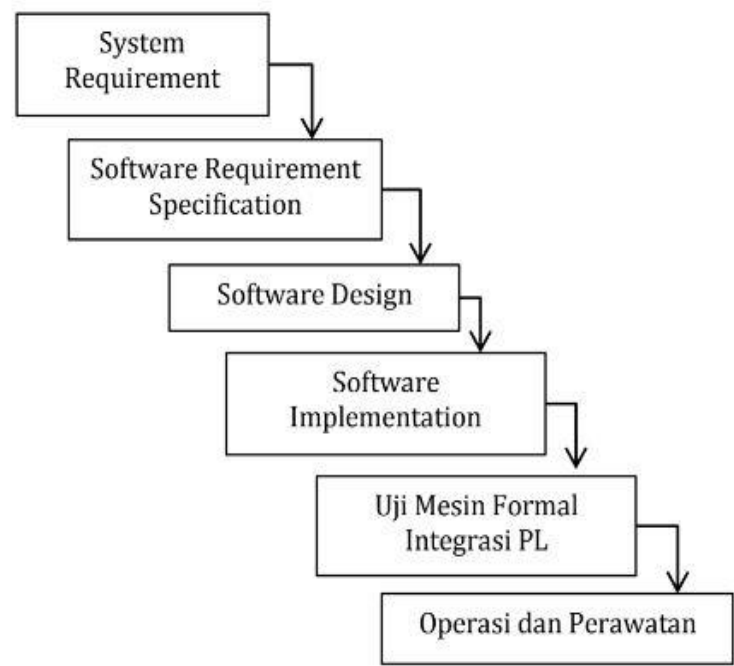

Gambar 1. Metode Waterfall

\section{HASIL DAN PEMBAHASAN}

Untuk dapat menggambarkan prosedur secara keseluruhan diperlukan beberapa tahapan analisa sebagai bentuk pengumpulan informasi guna mendapatkan model yang sesuai dengan kebutuhan dan mampu memberikan solusi dengan cepat secara efektif dan efisien, mulai dari tahapan pengumpulan informasi dan kebutuhan, analisa dokumen, merancangan hubungan antar 
dokumen sampai dengan merancanga model diagram database dan model rancangan sistem. Beberapa tahapan yang dimaksud sampai dengan model rancangan yang diciptakan dapat dilihat pada gambar berikut :

\subsection{Use Case Diagram Diusulkan}

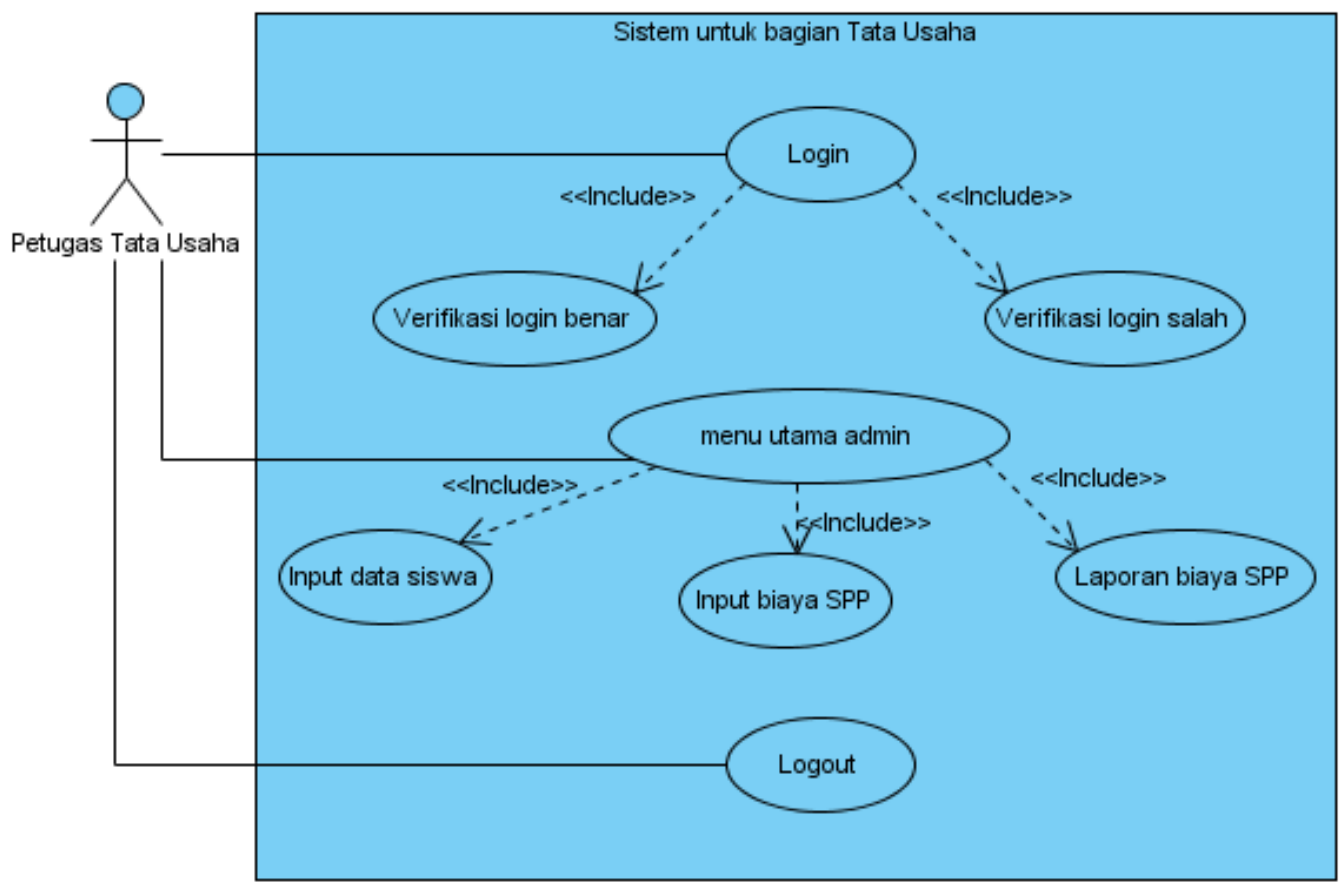

Gambar 2. Use Case Diagram

Pada usecase diagram terlihat bahwa petugas TU melakukan login terlebih dahulu dengan memasukkan username dan password yang benar, melakukan akses pada menu utama admin, Menu data siswa (tambah, edit, dan hapus data siswa), melakukan input biaya SPP setelah pembayaran akan muncul laporan biaya SPP, admin log out jika telah selesai.

\subsection{Activity Diagram Diusulkan}

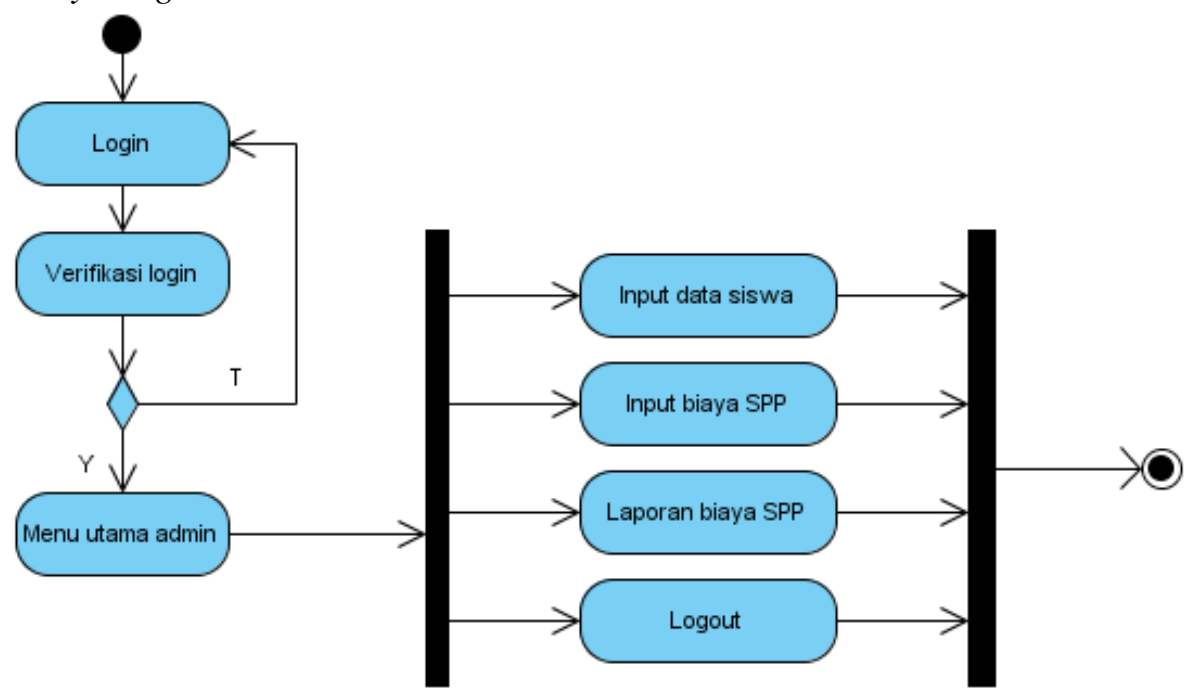

Gambar 3. Activity Diagram 
Pada activity diagram, admin harus melakukan login terlebih dahulu dengan memasukkan username dan password yang benar dengan hak akses dapat menginput, melihat, menyimpan, mencetak laporan.

\subsection{Squence Diagram Diusulkan}

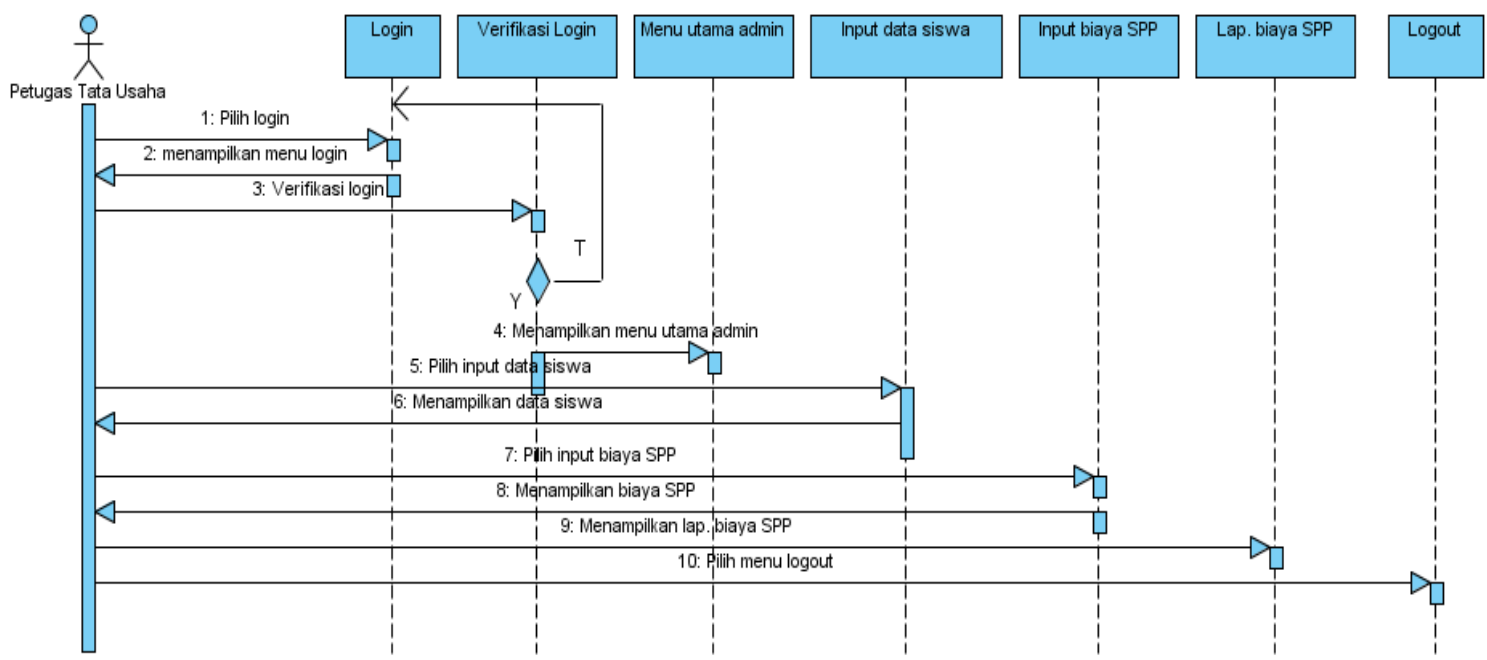

Gambar 4. Squence Diagram

Pada sequence diagram, Aktor I (TU) dapat melakukan login terlebih dahulu dengan memasukkan username dan password yang benar, setelah berhasil login, TU akan masuk ke menu dashboard. Selanjutnya, TU dapat menambah dan menapilkan data siswa, data input pembayaran dan menampilkan laporan SPP.

\subsection{Desain Rancangan Program}

Desain rancangan sistem informasi pembayaran SPP Pada SMK Arrahman Tangerang merupakan hasil dari implementasi perancangan sistem baru, diantaranya adalah :

\subsubsection{Tampilan Login}
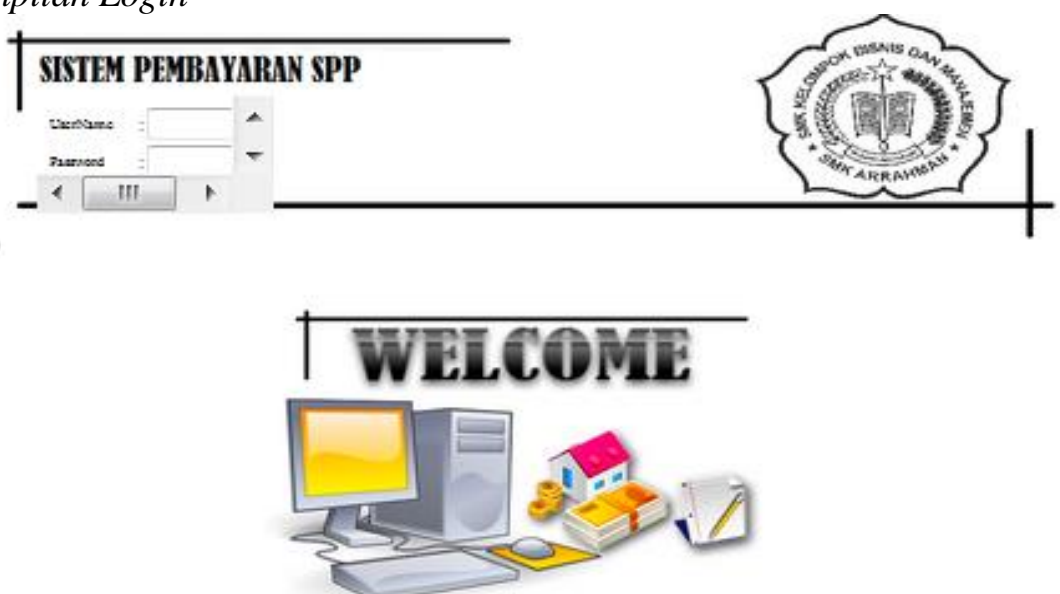

SMK ARRAIIMAN

Gambar 5. Tampilan Menu Login 
User dengan benar selanjutnya klik login dan setelah itu user dapat masuk kedalam sistem. Sedangkan kalau username dan password salah maka tidak akan dapat masuk kedalam sistem dan akan muncul tulisan bahwa username dan password yang anda masukkan salah

\subsubsection{Tampilan Menu Utama}
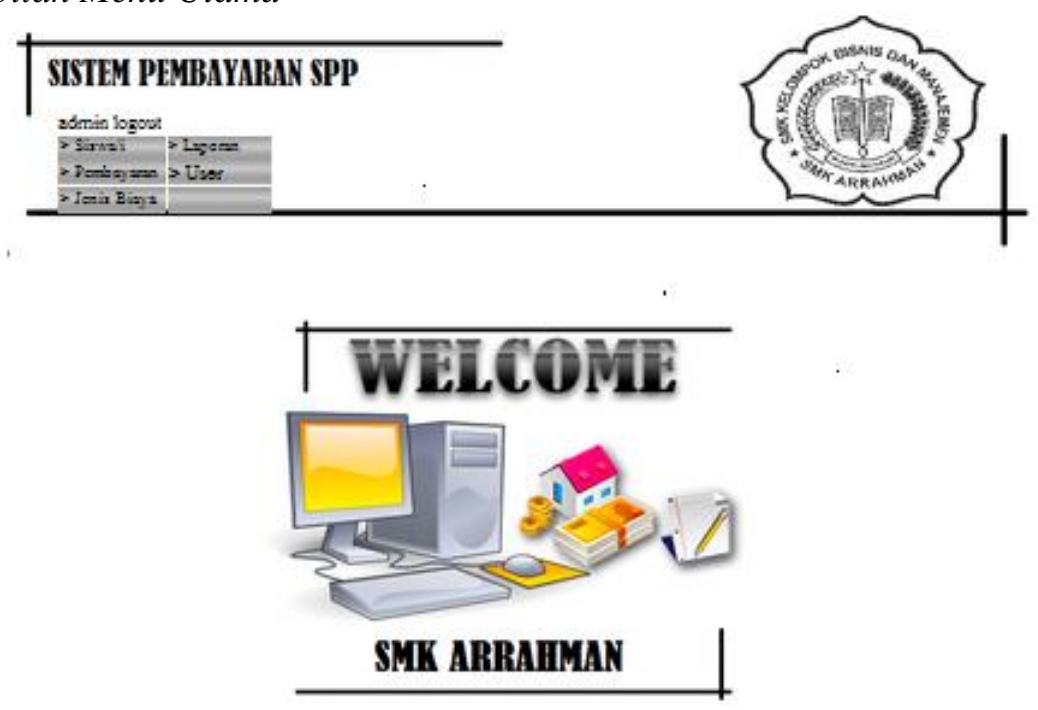

Gambar 6. Tampilan Menu Utama

Setelah login, user akan diarahkan ke menu utama sebelum melakukan penginputan atau pembayaran.

\subsubsection{Tampilan Menu Siswa}

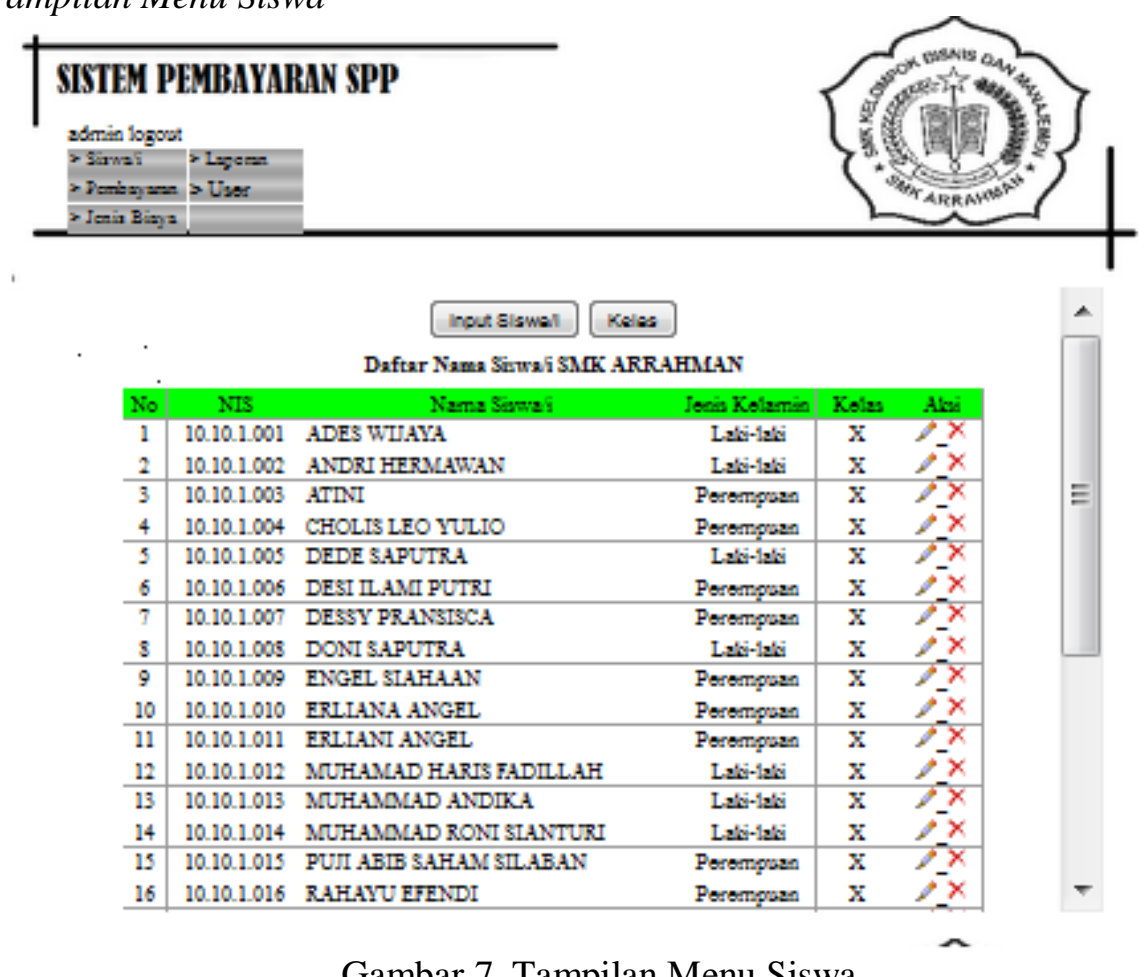

Gambar 7. Tampilan Menu Siswa 
Halaman ini berfungsi untuk menampilkan data siswa berupa nis, nama, dan jenis kelamin

\subsubsection{Tampilan Pencarian Siswa}

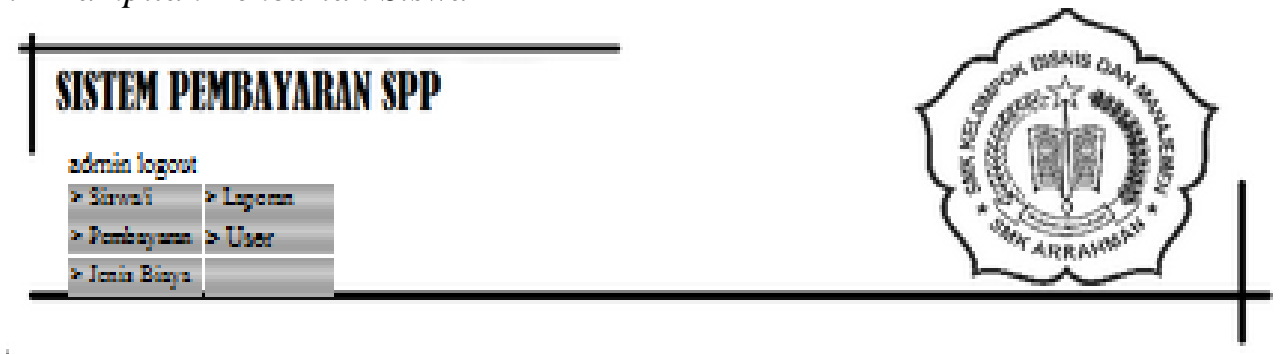

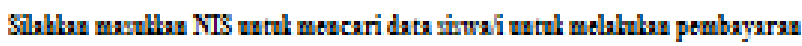

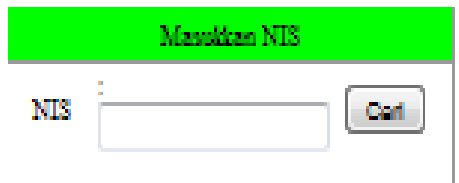

Gambar 8. Tampilan Pencarian Siswa

Halaman ini berfungsi untuk mencari data siswa dengan memasukkan no. NIS untuk melakukan pembayaran.

\subsubsection{Tampilan Menu Jenis Pembayaran}

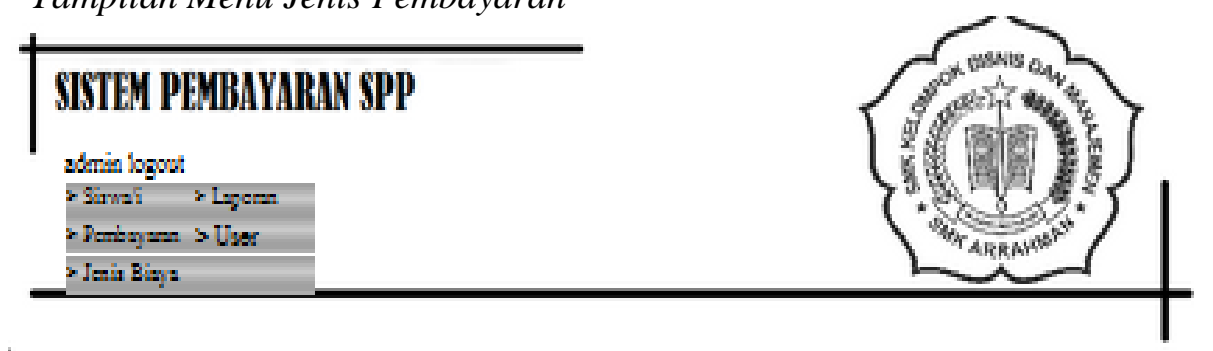

\section{nout deris Bloge}

\begin{tabular}{|c|c|c|c|c|}
\hline Kolas & Kods Bizyz & Nema Biaya & Jumiah Bisya & Alei \\
\hline ALL & ALLBM & Kompoter & 10000 & $2 . x$ \\
\hline $\mathrm{x}$ & X110BM & SPP & 100000 & p.x \\
\hline
\end{tabular}

Gambar 9. Tampilan Menu Jenis Pembayaran

Halaman ini berfungsi untuk menampilkan jenis pembayaran yang sudah siswa bayarkan 


\subsubsection{Tampilan Menu Laporan Pembayaran}

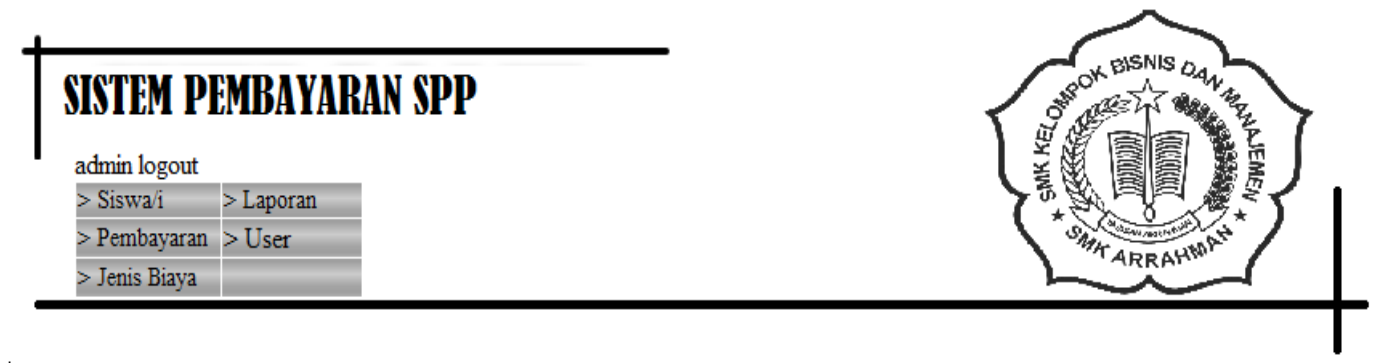

\begin{tabular}{|c|c|c|c|c|c|c|c|}
\hline \multicolumn{8}{|c|}{ Laporan Pembayaran } \\
\hline \multicolumn{8}{|c|}{ Cetak Laporan } \\
\hline No & NIS & Nama & Kelas & Pembayaran & Biaya & Tgl Bayar & Aksi \\
\hline 1 & 111210004 & Andriansyah & XII & Komputer & 50000 & 2013-09-19 & $x$ \\
\hline 2 & 111210004 & Andriansyah & XII & SPP & 200000 & 2013-09-19 & \\
\hline 3 & 131410008 & Fitri & $\mathrm{X}$ & Komputer & 100000 & 2013-09-18 & \\
\hline 4 & 131410007 & Hendri Ridwan & $\mathrm{X}$ & SPP & 300000 & 2013-09-18 & $x_{-}^{-x}$ \\
\hline 5 & 111210001 & Fatmah & XII & SPP & 200000 & 2013-09-18 & $e_{-}^{-} x$ \\
\hline 6 & 131410005 & Dedy A Pandi & $\mathrm{X}$ & Komputer & 50000 & 2013-09-18 & $x_{-}^{-} x$ \\
\hline
\end{tabular}

Gambar 9. Tampilan Menu Laporan Pembayaran

Halaman ini berfungsi untuk menampilkan laporan pembayaran yang dilakukan siswa.

\subsubsection{Tampilan Cetak Laporan Pembayaran}

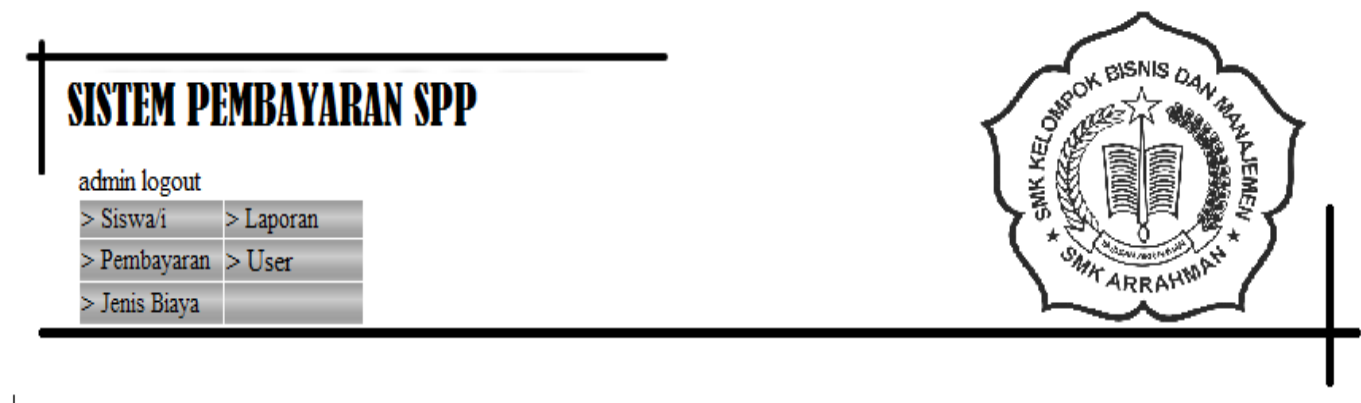

\section{Kembali}

Cetak Laporan SPP

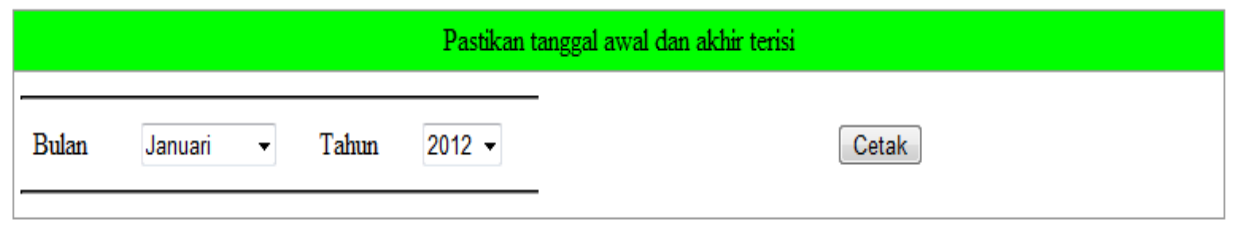

Gambar 10. Tampilan Cetak Laporan Pembayaran

Halaman ini berfungsi untuk melihat hasil laporan pembayaran yang masuk. 
3.4.8. Tampilan Cetak Laporan Keuangan

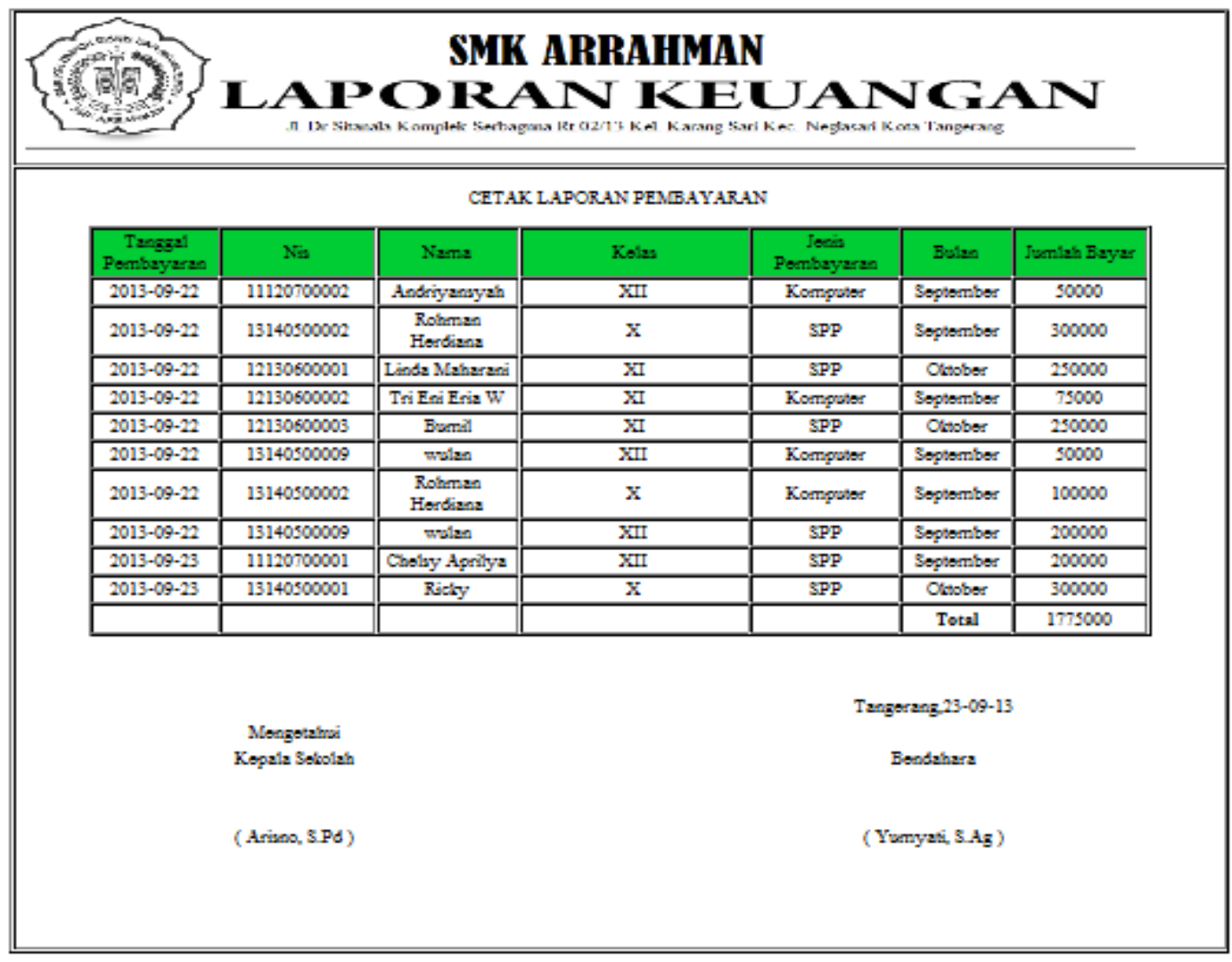

Sins

Gambar 11. Tampilan Cetak Laporan Keuangan

Halaman ini berfungsi untuk mencetak laporan keuangan.

3.4.9. Tampilan Cetak Kwitansi Pembayaran

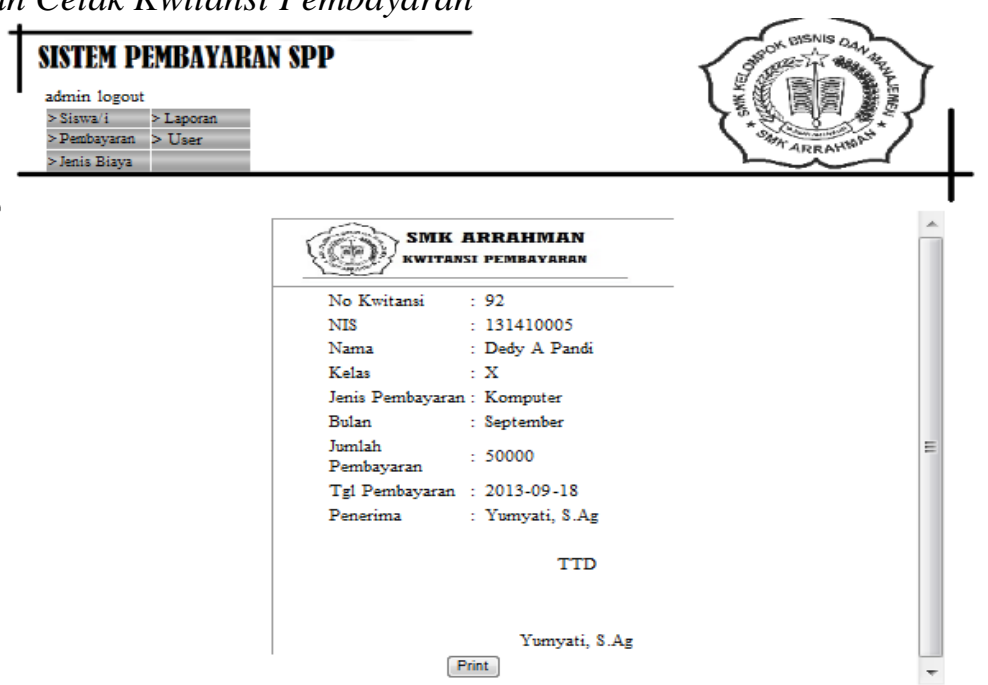

Gambar 12. Tampilan Cetak Kwitansi Pembayaran 
Halaman ini berfungsi untuk mencetak kwitansi pembayaran sebagai bukti bahwa siswa telah melunasi pembayaran.

\section{KESIMPULAN}

Dengan adanya sistem perancangan pembayaran SPP berbasis web akan sangat membantu untuk mempermudah dan mempercepat pekerjaan dalam sistem pembayaran, sehingga dapat memberikan efektifitas dan efisiensi yang lebih baik dalam proses pembayaran SPP.

\section{SARAN}

Namun demikian penelitian lanjutan perlu dilakukan untuk mengembangkan fitur-fitur tambahan yang lebih bermanfaat lagi.

\section{DAFTAR PUSTAKA}

[1] Savitri Gani, Evy. 2019. Perjanjian Terapeutik Antara Dokter dan Pasien. Sidoharjo: Uwais Inspirasi Indonesia

[2] Agency. Beranda. 2010. Menggali Harta Karun. Jakarta: PT. Elek Media Komputindo.

[3] Yurindra. 2017. Software Engineering. Yogyakarta: Penerbit Deepublish (Group Penerbitan CV Budi Utama)

[4] Siswanto, Ely. 2014. Good University Governance Prinsip dan Implementasi Dalam Penggalian Pendapatan. Malang: Gunung Samudera 